\title{
Method for Emissivity Estimation of Metals
}

\author{
Emőd FILEP, ${ }^{1}$ Dénes Nimród KUTASI, ${ }^{2}$ Lajos KENÉZ3 ${ }^{3}$ \\ Sapientia Hungarian University of Transylvania, Faculty of Technical and Human Sciences, Department of \\ Electrical Engineering, Târgu-Mureș, Romania \\ 1 efilep@ms.sapientia.ro \\ ${ }^{2}$ kutasi@ms.sapientia.ro \\ 3 l_kenez@yahoo.com
}

\begin{abstract}
Knowledge of the surface emissivity of metals is becoming more and more important both from the material science, process modelling and control point of view. Previous research results have shown that the emissivity of most metals depends on the temperature of the surface. It has also been reported that the most important temperature region is between $300-1000 \mathrm{~K}$ degrees, where the change of the emissivity is the most intense, which is also the most significant from a process control point of view [1]. We also report temperature dependent emissivity observed during plasma nitriding of low alloy steels [2]. Related to one of our present research topics the study of the low alloy aluminum (AlMg1, AlMg3) emissivity has prooven relevant. In this article the developed emissivity estimation model is presented. In the first part a literature overview and the theoretical approach of the new method is discussed, followed by the experimental results for low alloy aluminium emissivity determination and a comparison with the results available in the literature.
\end{abstract}

Keywords: emissivity of metals, aluminum, steel, process control, plasma nitriding.

\section{Emisszivitásmérési módszerek}

Thermal radiometry is one of the methods available for metal emissivity measurements, requiring a very well equipped laboratory [3]. In this method, the metal with unknown emissivity and a laboratory blackbody are placed aside then heated up to the same temperature. During heating, these two samples are alternately observed using radiometry. The emissivity corresponds to the ratio of the measured averages. Vitalion Teknillinen Tutkimuskeskus [1] suggested another method called VTT which is much easier to realize. According to this method, a well-defined rectangular shaped sample is heated in a furnace at $1000 \mathrm{~K}$ and the temperature continuously recorded until it reaches thermal equilibrium. Using mathematical models for the radiation, conductive and convective heat transfer components, the radiation component is separated from the experimental data and the emissivity thereby determined. The deviation of the results is estimated to be about $20 \%$, which is considered to be acceptable for practical applications. In the case of carbon steel the emissivity depends on the tem- perature, while in the case of stainless steel the emissivity is roughly constant. Detailed study of emissivity results of different Aluminum alloys is presented in [4]. In these experiments the radiation detection method is combined with temperature measurements using thermocouples. The emissivity of alloys with various surface properties is investigated at different wave-lengths and over a wide range of temperatures. It is pointed out that the emissivity of the Aluminum alloys strongly depends on the mentioned factors, highlighting the disadvantages of the temperature measurement methods using pyrometers, where usually a single wavelength is used and the other factors are set aside.

In the following sections a simple method is proposed for the emissivity measurement of different metals. Temperature dependence of the emissivity can be approximated using polynomial functions, which can be used for mathematical modelling of the temperature variation of the examined sample. Experimental results are presented for a cylinder shaped Aluminum rod. 


\section{The method}

The method we propose is based on the properties of the plasma reactor. We use a relatively long cylindrical sample which is placed coaxialyly with the plasma reactor axis. The temperature of the sample is measured on the bottom of the cylinder in the on-axis position. The sample is heated up to about $900 \mathrm{~K}$ degrees in an abnormal plasma discharge using nitrogen as the working gas, maintaining 300Pa pressure. After reaching the desired maximum temperature, the gas inlet valve is closed. Keeping the vacuum-pump running, the pressure rapidly decreases, the cathode fall region boundary reaches the anode wall, and hence the plasma discharge burns out. From this moment the sample starts to cool down, while the pressure inside the plasma reactor remains under $1 \mathrm{~Pa}$ value. In the meantime, the process controller PC records the process parameters. Due to the low pressure and the low heat conductivity of the nitrogen gas, convective heat transfer is impossible, conductive heat transfer rate is very low, thus the sample cools down due to radiation heat transfer. In addition, the mathematical model can be further simplified owing to the fact that the surface of the sample is one magnitude lower than the plasma reactor surface. The schematic principle of the system is presented in Figure 1 and detailed description in [5].

\subsection{Theoretical background of the propo- sed method}

Based on the statements in Section 1. the radiated heat power of the sample can be written as [6]:

$$
P=\sigma \cdot S \cdot\left(e_{1} \cdot T^{4}-e_{2} \cdot T_{2}^{4}\right),
$$

where:

$\sigma=5,67 \cdot 10^{-8} \mathrm{~W} / \mathrm{m}^{2} \mathrm{~K}^{4}$ the Stefan-Boltzmann constant,

$S$ : the surface of the sample: $d=0,06 \mathrm{~m}, h=0,24 \mathrm{~m}$

so $S=0,05 \mathrm{~m}^{2}$,

$T$ : the temperature of the sample;

$e_{1}$ : the emissivity of the sample (which usually depends on the temperature),

$T_{2}=300 \mathrm{~K}$ the temperature of plasma reactor's water-cooled wall,

$e_{2}=0,3$ the emissivity of the plasma reactor inner wall (anode).

The usage of the above mentioned value of the wall emissivity can be justified by the preliminary experiments described in [4]. Even though the wall of the plasma reactor is made of Aluminum, due to the hundreds of hours of nitriding

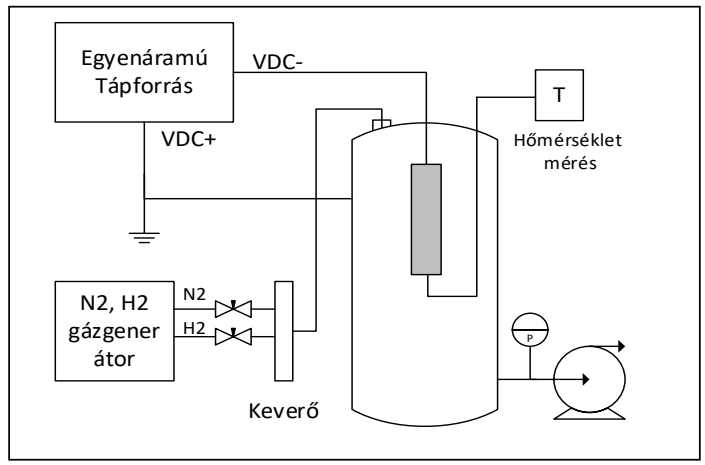

Figure 1. Schematic principle of the plasma nitriding equipment

experiments, its surface is already covered by sputtered Fe atoms and an Fe-nitrite layer.

After plasma burnout, the temperature of the sample decreases continuously, while the radiated heat power results in the decrease of the internal energy of the sample.

$$
\begin{aligned}
\frac{d Q}{d t} & =m \cdot c_{A l}(T) \cdot \frac{d T}{d t}= \\
& =\rho \cdot \frac{\pi \cdot d^{2}}{4} \cdot h \cdot c_{A l}(T) \cdot \frac{d T}{d t},
\end{aligned}
$$

where:

$$
m=\rho \cdot \frac{\pi \cdot d^{2}}{4}=1,832 \mathrm{~kg} \text { the weight of the sample, }
$$

$\rho=2700 \mathrm{~kg} / \mathrm{m}^{3}$ the density of Aluminum, $c_{A l}\left(T_{0}\right)=910 \mathrm{~J} / \mathrm{kgK}$ the specific heat of Aluminum at normal temperature (specific heat vs. temperature is presented in Figure 6.),

$\frac{d T}{d t} \quad$ is the cooling speed.

The model can be refined taking into account the heat loss due to heat conduction of the cathode suspension. The cathode is suspended by a ceramic insulated $12 \mathrm{~mm}$ diameter, $120 \mathrm{~mm}$ long steel rod, which transmits the conducted heat power to the water-cooled top flange of the plasma reactor. The conducted heat power through the cathode suspension rod is $P_{c d}$ :

$$
P_{c d}=\lambda_{r f} \cdot \pi \cdot R_{r f}^{2} \cdot\left(T-T_{2}\right) / l_{r f} \quad,
$$

where: 
$\lambda_{r f}=16 \mathrm{~W} / \mathrm{mK}$ the thermal conductivity of the cathode rod,

$R_{r f}=6 \cdot 10^{-3} \mathrm{~m}$ the radius of the cathode rod,

$l_{r f}=0,12 \mathrm{~m}$ the length of the cathode rod.

According to our calculations, the conductive heat power corresponding to the $900-300 \mathrm{~K}$ temperature range (plasma discharge burnout - thermal equilibrium) is:

$$
P_{c d}(\max )=9,06 \mathrm{~W} \text {, }
$$

which is less than $2 \%$ of the total power.

Based on formula (1), (2) and (3) the thermal equilibrium equation valid for the cooling process can be written as:

$$
\frac{d Q}{d t}=P_{r a d}+P_{c d} .
$$

From this equation, the emissivity of the sample can be written as:

$$
\begin{aligned}
& =\frac{m \cdot c_{A l}(T) \cdot \frac{d T}{d t}+e_{2} \cdot \cdot S \cdot T_{2}}{\cdot S \cdot T}- \\
& \frac{\lambda_{r f} \cdot \pi \cdot R_{r f} \cdot(T-T)}{r f} \\
& . S \cdot T
\end{aligned}
$$

Introducing the temperature of the sample $(T)$ and the corresponding cooling speed $(d T / d t)$ in formula (6), the $e 1(T)$ function for the investigated temperature range can be found.

\subsection{Measurements, results}

The sample, an extruded Aluminum rod, was washed with hot water, detergent, distilled water and finally with absolute alcohol and it was coaxially mounted on the cathode with an M12 thread. To measure the temperature, a $4 \mathrm{~mm}$ diameter coaxial hole was drilled in the bottom of the sample.

The temperature was measured with a Chromel-Alumel thermocouple, having a thermally isolated Aluminum-oxide cover, and an external diameter of $2 \mathrm{~mm}$. The signal was interfaced by a galvanic separator. The abnormal gas discharge was ignited in pure hydrogen at $50 \mathrm{~Pa}$ to clean the surface from contamination.

The voltage and current curves in Figure 2. show that the cleaning was maintained for 45 minutes with constant arc generation. Then the discharge stabilized and warming started. By increasing the nitrogen flow rate, reaching $220 \mathrm{~Pa}$ in the reactor, the warming accelerated, but new sparks occurred until the temperature exceeded $300^{\circ} \mathrm{C}$. At 1200 Watts (600V, 2A) the gas supply was removed, the power supply increased the voltage to $1000 \mathrm{~V}$, the pump reduced the pressure to $1 \mathrm{~Pa}$ (Figures 2. and 3.).

The rapid decrease and interruption of the current can be observed. We could see the growth of the cathode dark space, at $1000 \mathrm{~V}$ the power supply was switched off.

After the switch off, based on the recorded values of $\mathrm{T}=\mathrm{f1}(\mathrm{t})$ (Figure 4.) and the corresponding $\mathrm{dT} / \mathrm{dt}=\mathrm{f} 2(\mathrm{t})$ derivative (Figure 5 ), the emissivity of the sample was determined using (6). In the calculation we have to take into account the temperature dependence of the specific heat, the change of the specific heat in the temperature range we examined is shown in Figure 6.

The result of the emissivity calculation is shown in Figures 7 and 8. Under the described conditions, the emissivity of the Aluminum varies between 0.34 and 0.39 , increasing with increasing temperature. The deviation of the results is large, around $10 \%$, but this is not greater than the value reported in [1].

In the emissivity calculation, the derivative of the cooling curve is not smooth because the measurement noise is amplified during the derivation. Calculations were also made with the filtered derivative curve (Figure 9). The results are shown in Figures 10 and 11. The obtained results do not differ significantly from the previous results, the calculated emissivity is oscillating following slight fluctuations in the derivative curve. During our research, we examined the uniformity of the radial temperature distribution in the sample. Because of the particularly good thermal conductivity of Aluminum, the radial temperature gradient is small, as shown in Figure 12. This simulation allowed us to consider the temperature of the sample to be uniform.

\section{Conclusions}

In this paper we have presented an experimental method to determine the emissivity of a metal, which is easy to perform in the plasma reactor. The obtained results are suitable for several purposes e.g. study of the plasma nitriding process modelling the temperature variation of the sample, thermal emissivity measurement of nitrided samples, or any other cases where surface sputtering and arc discharges are not disturbing effects. Subsequently, this method is not suitable in the case of shiny surfaces. The results of our experiments have shown that the variation of a sample's 

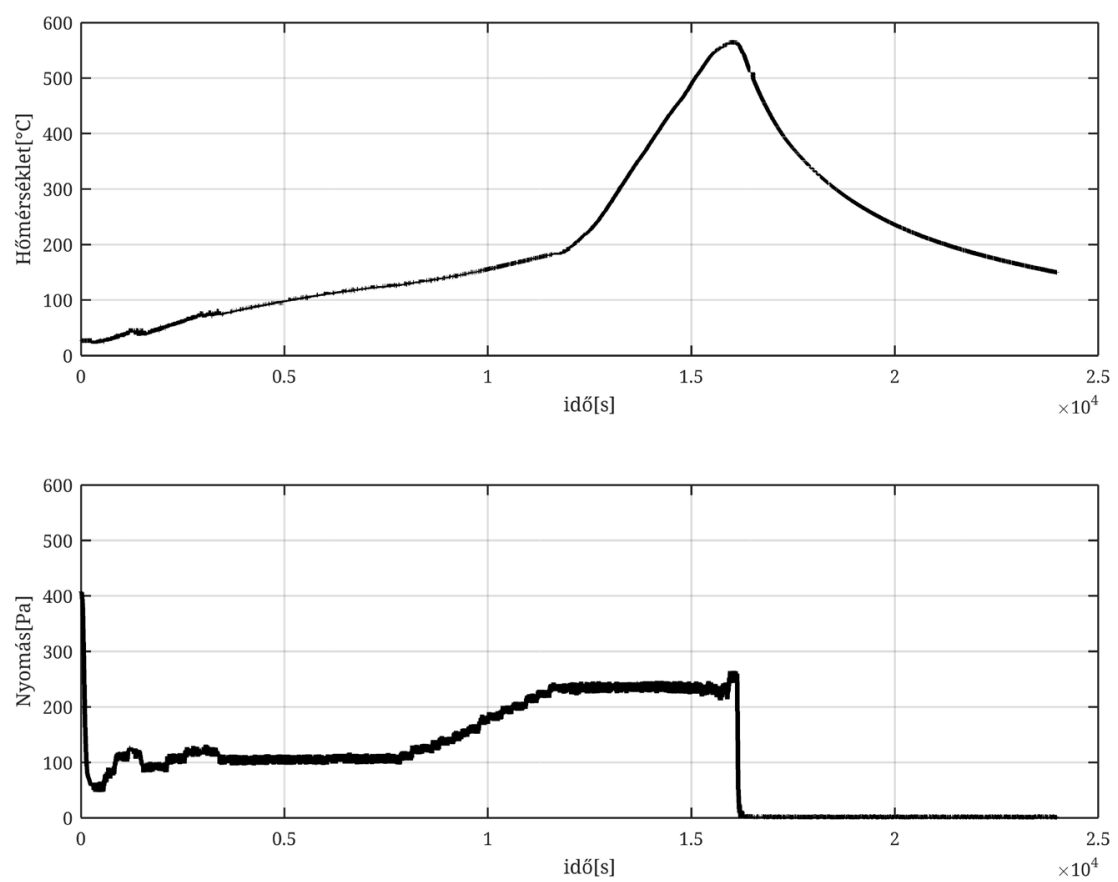

Figure 2. Temperature and pressure in the reactor
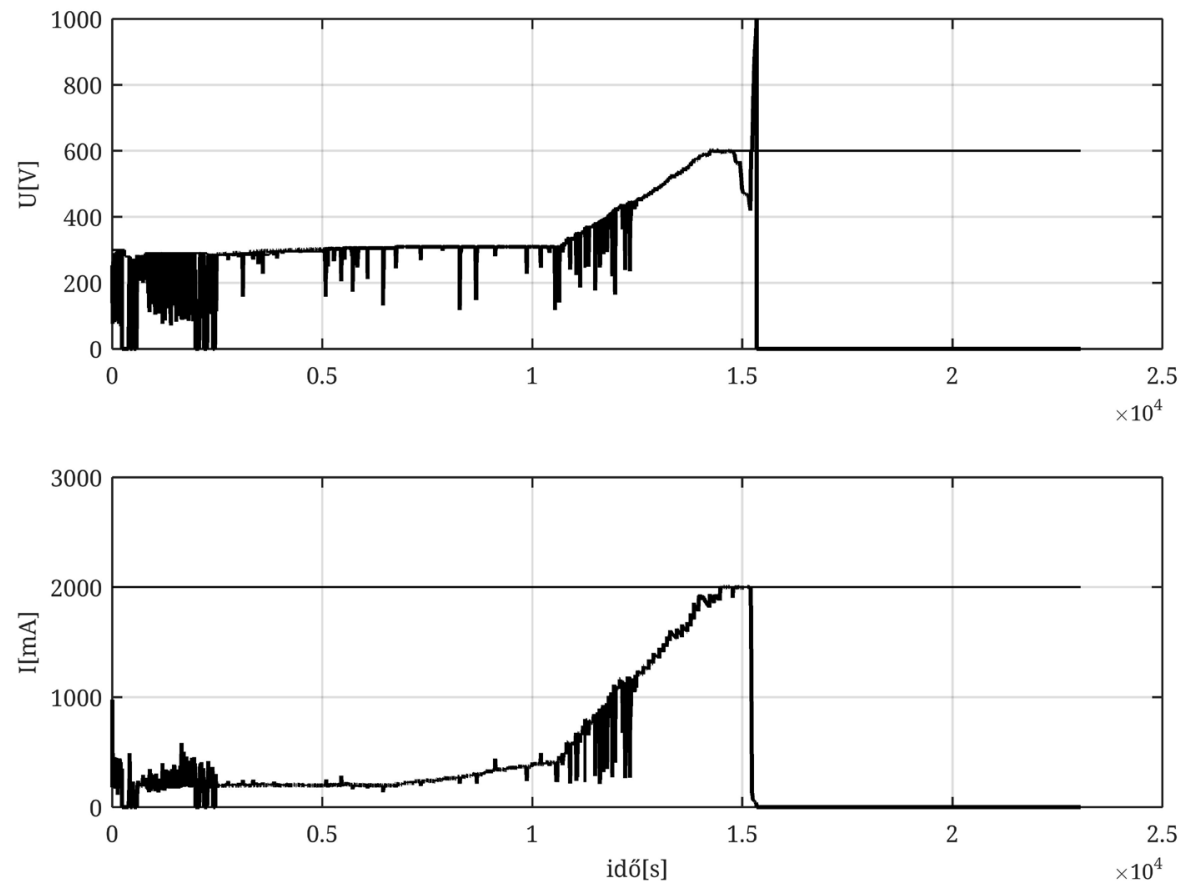

Figure 3. AVoltage and current between the elec-trodes in the reactor 


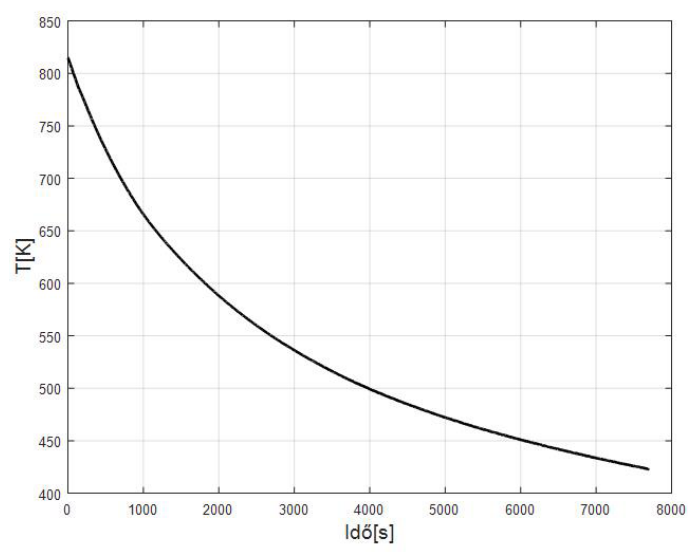

Figure 4. $T=f(t)$ cooling curve

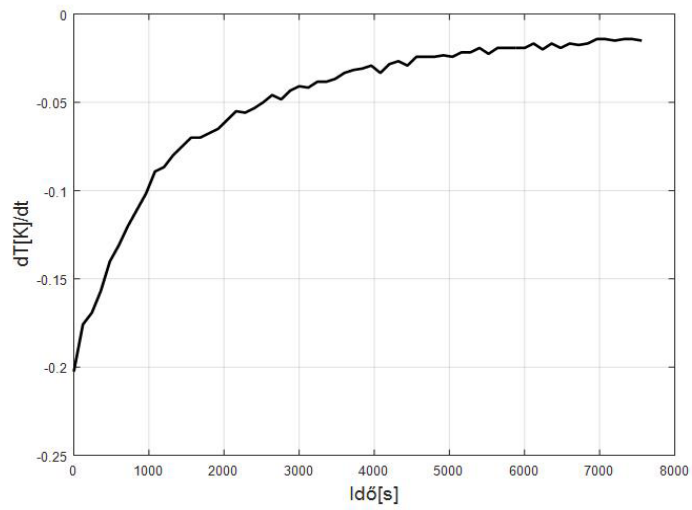

Figure 5. Time based derivative of the cooling curve

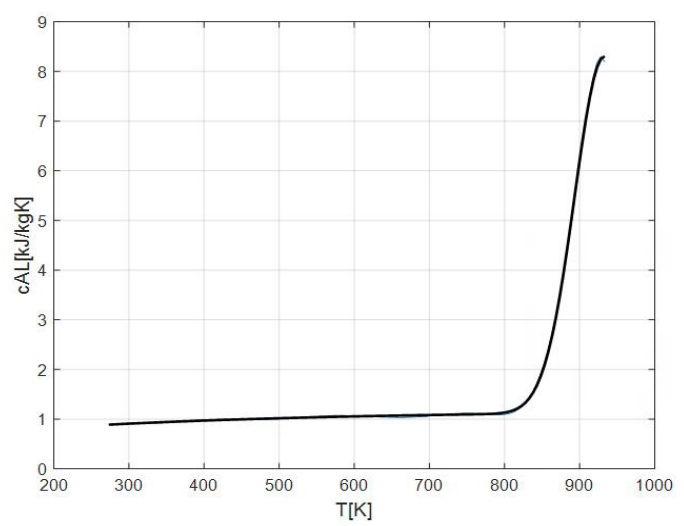

Figure 6. The specific heat-capacity of the alu-minum versus temperature

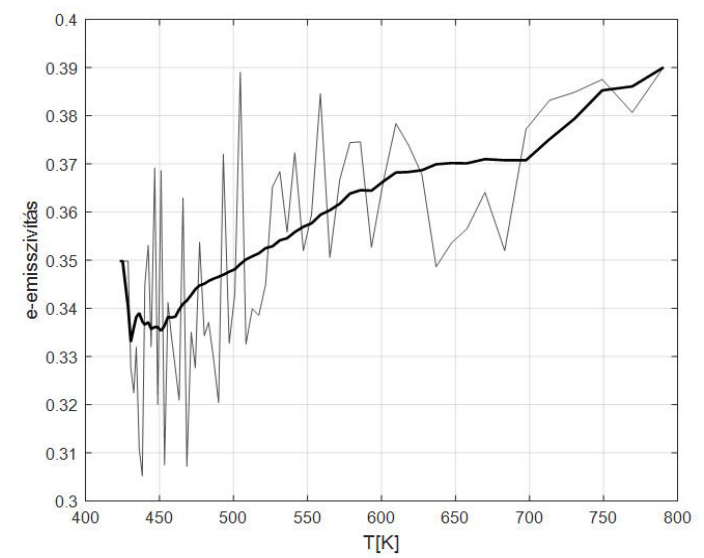

Figure 7. Emissivity of the aluminum versus tem-perature. In the figure the calculated emissivity and its mean value is depicted

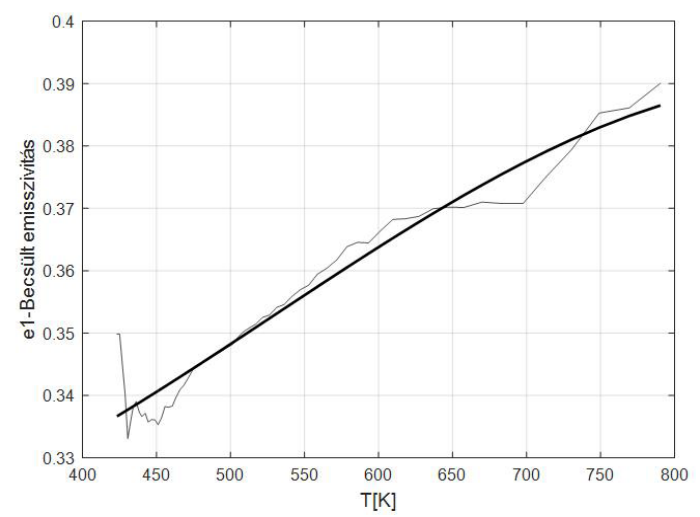

Figure 8. Polynomial approximation of the calcu-lated emissivity

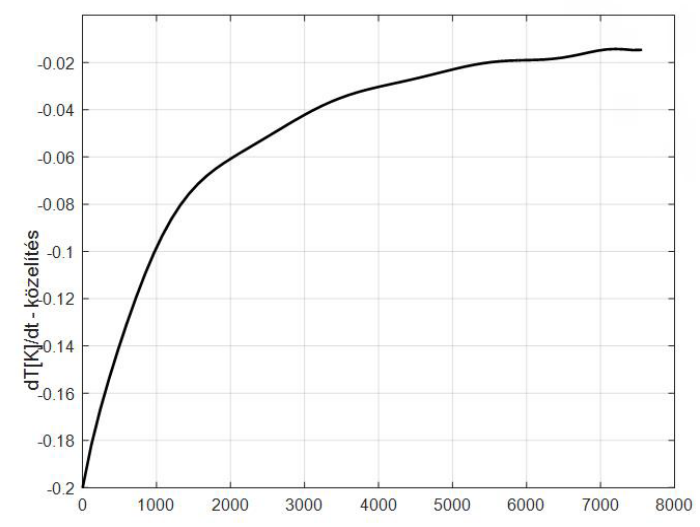

Figure 9. Filtered derivative of the cooling curve 


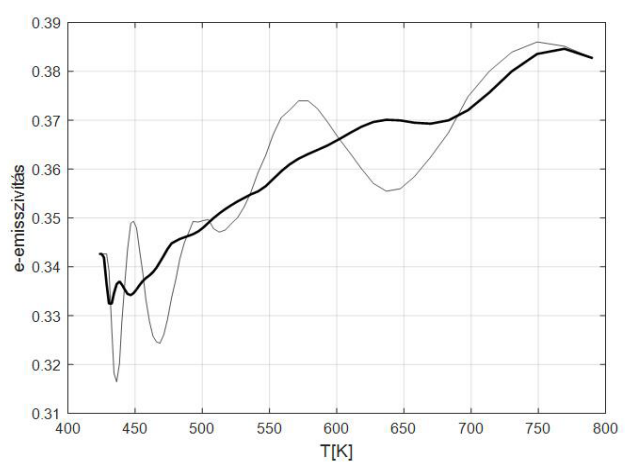

Figure 10. The emissivity of the Aluminum calcu-lated with the filtered derivative curve

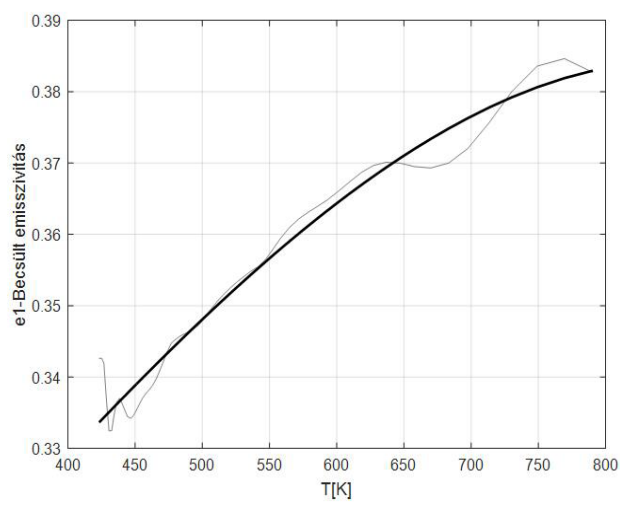

Figure 11. Polynomial approximation of the calcu-lated emissivity, with filtered derivative curve

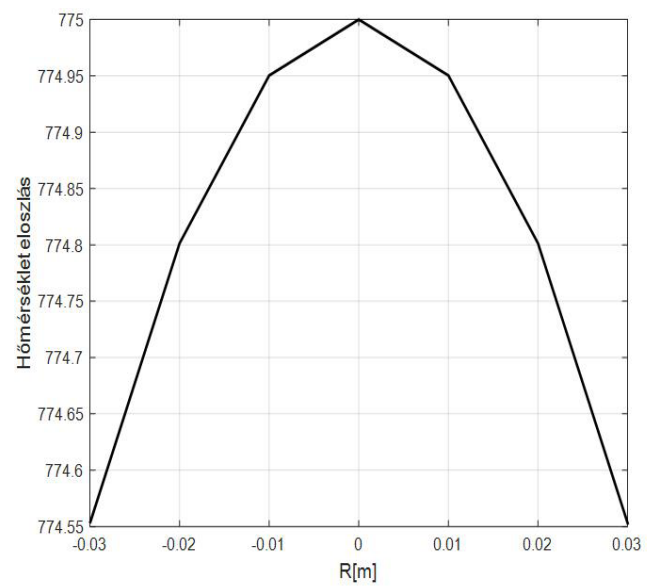

Figure 12. Radial temperature distribution in the sample

temperature can be modelled using the thermal emissivity. In addition, we have also shown that in the case of some low alloy steels the emissivity depends significantly on the temperature of the sample. In this case it is very important to use the method presented in this paper. Finally, we have shown that the emissivity of the Aluminum alloy rod used in our experiments is almost constant in the examined temperature range.

\section{Acknowledgement}

The authors would like to thank Institute of Research Programs of the Sapientia University (KPI) for supporting the research project and for the research grants accorded over the years. The authors would like to address special thanks to András Kelemen PhD who, as referee of the paper, suggested that the heat capacity of the Aluminum depends on the temperature. Taking this suggestion into account, our results have become much more reliable.

\section{References}

[1] Paloposki T., Liedquist L.: Steel emissivity at high temperatures. VTT Research Notes 2299, Otamedia Oy, Espoo, 2005.

https://www.vtt.i/inf/pdf/tiedotteet/2005/T2299.pdf

[2] Kutasi N., Filep E., Kenéz L.: Heat transport modelling and adaptive model predictive temperature control of the direct current plasma nitriding process performed in a linear non-isotherm plasma reactor. Journal of Control Engineering and Applied Informatics, 19/4. (2017) 52-60.

http://www.ceai.srait.ro/index.php?journal=ceai\&page $=$ article\&op=view\&path $\% 5 B \% 5 D=4468 \&$ path $\% 5 B \% 5 \mathrm{D}=1466$

[3] Liedquist L.: A radiometric method for measurement of emissivity of metallic surfaces. Non Nuclear Energies Workshop on Optical Property Measurement Techniques, Ispra, 1987. 277-280.

[4] Wen C. D., Mudawar I.: Experimental investigation of emissivity of aluminum alloys and temperature determination using multispectral radiation thermometry (MRT) algorithms. Journal of Materials Engineering and Performance, 11/5. (2002) 551-562.

https://doi.org/10.1361/105994902770343818

[5] Filep E., Kutasi N., Kenéz L.: A Sapientia EMTE marosvásárhelyi karának plazmareaktora. Múzeumi Füzetek - Acta Scientiarium Transylvanica, Chimica, 25/3. (2017) 69-76. http://hdl.handle.net/10598/30171

[6] Siegel R., Howell J. R.: Thermal radiation heat transfer. McGraw-Hill, New York, 1972. 